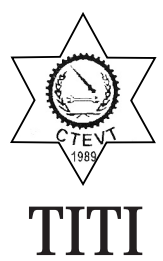

Journal of

Training and Development

2017, Volume 3

ISSN: 2392-456X(Print)

DOI: http://dx.doi.org/10.3126/jtd.v3i0.18228

ISSN: 2392-4578(Online)

\title{
An Ethnographic Inquiry on Injecting Drug Users towards Vocational Training
}

\author{
Amit koirala \\ Former Trainer, Research and Development Department \\ Training Institute for technical Instruction (TITI) \\ Sanothimi, Bhaktapur, Nepal \\ Email for Correspondence: amit_me63@yahoo.com
}

\begin{abstract}
In this study, I pursued to gain an in-depth understanding on vocational education and training (VET) of injecting drug users residing in rehabilitation in Kathmandu valley. Two rehabilitation centers that accommodate institutionalized injecting drug users were purposively selected for the study in which six participants voluntarily participated. An ethnographic narrative enquiry, which is the qualitative research methodology, was employed to gain insight into their lived experiences and perception towards VET. The themes that emerged from the findings were interspersed by focusing on a range of sociological theories. This study brings to the fore that injecting drug user has affirmative impression towards VET and understands the importance of VET but is not willing to study anymore. Participants' perception understood earning money is more important than getting VET and they understood that it is too late to study and they are not able to study any more due to the use and abuse of drugs and their study habits have been destroyed by the drugs.
\end{abstract}

Keywords: Injecting drug users; rehabilitation center; vocational education and training.

\section{Introduction}

Drug abuse has been reported in almost every corner of the world. Drug use in Nepal is not a new phenomenon. Use of substances such as alcohol and cannabis in Nepal book back to centuries associated primarily with religious rituals and traditional festivals and consumed by both participants and observants (Sinna, 2009).

Drug use in Nepalese youth is often associated with lack of proper guidance by parents and exposure to western cultures. Some parents, especially father working aboard are often absent during the growing age of their children. Such parents though might make good money for the family, are unable to supervise what the children to do with the money. Similarly, in household run by mothers where husband are absent due to work or other reason, it appears that some mother are unable to control their grown-up youngsters, which may leads to drug abuse (Dhital, Subedi, Gurung \& Hamal, 2001).

United Nation Office of Drug Control [UNODC] (2011) states that in Nepal, the topography, 
environmental degradation, poverty and economic migration are all linked and they combine with other factors to increase vulnerability to drug-abuse driven HIV infection. Similarly, UNODC (2011) states that Nepal has also entered the stage of a concentrated epidemic with HIV/AIDs prevalence. In Nepal Injecting Drug Users (IDUs) are seen a major high risk group, among others such as sex workers.

Aryal (2010) reveals that in Kathmandu Valley, 17458 were estimated to be the hard drug users in which 15580 are male and 1875 are female. Similarly current age distribution for hard drug abuse in 2010 were $1.2 \%$ less than $15,21.6 \% 15-19,31 . \%$ 20-24, $21.8 \% 25-29,12.8 \% 30-34,7.4 \% 35-39$, and $4.2 \%$ 40 years and above. Similarly author also states that age at first drug intake less than 15 years were $19.7 \%$, $15-19$ were $53.4 \%, 20-24$ years were $18.2 \%$ and 25 and above years were $8.7 \%$. Aryal (2010) also states that hard drug users currently attending to school or campus were $14.4 \%$ where as not attending were $85.6 \%$. Out of the total hard drug user $61.4 \%$ were using through Intravenous route where as remaining $38.6 \%$ were using orally. Also in this study, I found that $21.1 \%$ of hard drug users visited to the rehabilitation centre where as $78.9 \%$ hard drug users have not visited to the rehabilitation centre.

Sinha (2009) states that drug rehabilitation center are the place or institutes or organization where drugs users or abusers are kept to change their knowledge, attitude and practice or behavior in respect to drug use and abuse. Rehabilitation center also helps to uplift an individual through different VET so that drug users can rehabilitate in their society through VET programme. In Nepal there are more than 35 drugs rehabilitation center and in Kathmandu valley only i.e. Kathmandu, Bhaktapur and Lalitpur districts there are 18 rehabilitation center (Sinha, 2009). In these drug rehabilitation centers, drug users are kept and treated to change their attitude towards drug abuse including their social and behavioral attitude (Sharma, 2007).

Smith (2014) states that vocational education and training (VET) is designed to deliver work specific skills and knowledge; VET covers wide range of careers and industries, including trade and office work, retail, hospitality and technology. Richard (2011) states that vocational rehabilitation is a process which enables persons with functional, psychological, developmental, cognitive and emotional impairments or health disabilities to overcome barriers to accessing, maintaining or returning to employment or other useful occupation.

So, from the above literature, I understand that drug abuse brings negative effect on physical and mental wellbeing of the individual. It also leads to problem related to work performance, family and social relationship. Drug use and abuse is also associated with crime and a prominent factor for human immune deficiency virus (HIV) epidemics in many parts of the world. Once an individual gets addiction on drug, it makes their life curse and after realization of drug abuse, demerits take necessary effort for harm reduction through drug rehabilitation. Since there is a narcotic drug control law prevalent in Nepal but still there is a gap is a practice due to the ineffective way to control the drug abuse in society. Though 18 rehabilitation centers are in operation inside Kathmandu Valley (Sinha, 2009) and many injecting drug users have taken service from this rehabilitation centers but only limited amount of research have been done in respect to IDU's residing in these rehabilitation center especially in understanding perception towards VET. While reviewing the literature, I found that more quantitative research have been done in these rehabilitation center so, there is a gap in understanding IDU's perception towards their vocational education and training which is also my problem of the study and to address this problem, this research especially tries to explore the perception of drug users towards their vocational education and training who are in the phase of harm reduction.

\section{My Research Method: Ethnographic Journey} Ethnography is also known as the study of social interactions, behaviors and perceptions which occur 
within groups, organizations, and communities (Brewer, 2005). Here in this study, I was present as an ethnographer because I studied social interaction, behavior and perception which occur within injecting drug users residing in rehabilitation center towards VET. According to Brewer (2005), the central aim of ethnography is to provide rich, holistic insights into people's views and actions, as well as the nature they inhabit through the collection of detailed observations and interviews. Here in this study I have attempted to provide rich, holistic insight of injecting drug users views and actions as well as their nature they inhabits through the collection of detailed interview and observation. As Atkinson and Hammersley (2007) states, the central task of an ethnographers is to document the culture, the perspectives and practices, of the people in their natural settings. Thus, I have also documented the culture, their perception and practice of injecting drug users in their natural settings. Here I aimed to get inside the way of injecting drug users how they see the world in respect towards VET.

According to Brewer (2005), ethnographers typically gather participant observations through direct engagement and involvement and likewise ethnographers need to record a variety of elements in their field notes and also gather formal in-depth interviews and documentary data such as minutes of meetings, diaries and photographs. So here in this study, I have gathered participant observation through my direct involvement and also recorded information through in-depth interview in diaries and my recorder. According to Atkinson and Hammersley (2007), in ethnographic research, participants are sampled on an opportunistic or purposive basis here in this study I have selected my twelve participants in purposive basis.

Analysis of ethnographic data is undertaken in an inductive thematic manner where data are examined to identify and to categorize themes and key issues that emerge from the data (Brewer, 2005). Through a careful analysis of my data, using this inductive process, I have categorized themes and key issues and generate theoretical explanations from my empirical work. Similarly, Brewer (2005) further more states that field work is often time consuming and data collecting can last for month/s or even year. So here I was also engaged in field work for a month.

\section{Injecting drug users perception towards Vocational Education and Training}

Rupesh (pseudo name, 21 years old male from Kathmandu residing in Our new home Rehabilitation centre, Godhawari, Lalitpur) knows the importance of vocational education and training in his life but he was pessimistic about his VET. He says: VET is an important aspect in our life but as like water flows on river which never come back to its same place, the same happened to me. I wanted to become a pilot and also I studied well to become a pilot but because of friends circle, I became a drug addict.

From the narration of Rupesh, I made a meaning was that injecting drug users knows the importance of VET in their life but the use and abuse of drugs made their study unmanageable and incomplete. Goode (2011) also claims that peer groups provide favorable environment for the use and abuse of drugs. Singh and Rajpoot (2012) also state that due to drug use and abuse it makes an individual, family and educational life unmanageable.

Rupesh has passed SLC. He got involved in drug abuse when he was studying at higher secondary level. After that his study got stagnant. He furthermore says:

"When I look back ward, some of my friends are now doctor and some Pilot. They all are in good condition but my faith is like this. I convince myself like this and I feel so regret."

Listening to the Rupesh's voice, I made meaning was that injecting drug users feels regret of their study. They feel more regret when they look backward and their peers who have done well on their studies. He realized that he had to study and said, "I feel regret when I see junior brother have 
done a good progress. Now when I start my studies I have to start with small brothers which does not fits for me. I have joined private VET course also but I can't complete it. It's all due to my drug habit."

From the interview of Rupesh, I again gained insight that injecting drug users feel guilty of their study not only of their peer who have done well on their study but also their junior brother and sister who have done good progress on their study. I also found Anup (pseudonym) feels shy to study with junior brother and sister even in VET course. From the interview of Anup, I made meaning was that rehabilitation centers were providing favorable environment where drug users were able to realize their past mistake from their experience and their schooling. Niraula, Singh, Nagesh and Shyangwa (2006) also state that one of the role of rehabilitation centers were to provide enabling environment where drug users could think and realize their past and go forwards for their new life.

Raju (pseudo name, 19 years old male from Kathmandu residing in Our new home Rehabilitation centre, Godhawari, Lalitpur) is also pessimistic about his education. He regrets his education. When he thinks about his education he says,

"When I think about my studies I feel very regret. I have to do well, I had such feeling. I was a brilliant student. I always used to get high marks $80 \%$ and above. But now when I think my studies I feel very regret."

Raju gives emphasis on VET saying VET is vital things for every human being. VET helps to make an individual to gain in specific skills and knowledge but between these ten to eleven years of his life, education with addiction also came. He further more says:

"Because of addiction, I went against education. What happens when we studies, by studies what can we do such feelings used to come in my mind. I was totally motivated with drugs and self centered, I never response with others and left my studies. After three years of gap of my studies I got married. I also got good opportunities but I could not grasp the opportunity because of drugs. I still regret that I should have studied at that time but now I am interested to take VET course so that I can run my family and economic life."

From the interview of Raju, I inferred that use and abuse of drugs not only make individual negative feeling towards peers, family and society but also in education also. Use and abuse of drug make one lose the education and also disconnects from different opportunities. At rehabilitation center when injecting drug users try to reflect their schooling and education, they feel guilty and regret. In this regard, Shangwa, Joshi \& Lal (2007) state that use and abuse of drugs were prevalent among high academic achievers but if the intake of drugs goes on increasing than that makes the degradation of academic outcome which finally may result to drop out of the students.

Dev (pseudo name, 34 years old male from Bhaktapur residing in Hamro Ghar Rehabilitation centre, Thimi, Bhaktapur) had passed SLC and after SLC he says that he had started to use drugs. Then after, his study went in vain. He says:

Now I can't study. I have forgotten everything that I had studied previously. Now, I will encourage my children to study.

He was pessimistic about his education but knows the value of VET. He further says:

"Education is not an important aspect in my life but VET is important aspect for me. After SLC, I went to college for further studies but I just went to college only, I didn't pay attention to my studies only on either money or drugs. When I started using drugs then my parents told me to get married. They thought that after marriage I will leave drugs but it was not possible for me. Now I will concentrate on my children future studies but for earning no one gives me job and family are not willing to sponsor for any business so, VET course is 
good option for me but I don't know which VET course I will do it."

From the interview with Dev, I made meaning was that if an individual is in drug use and abuse and getting that individual to marriage does not let him/her to quit the use and abuse of drug. Here my participant got married so that he may get rid of injecting drug but that didn't happened. My participant quit his study and his family life also got worsened. Madhav and Yadhav (2012) also states that the use and abuse of drugs leads towards physiological and psychological dependency towards drugs which creates regular threat to their family and worsen their family life with an unexplained reason.

Prakash (pseudo name, 20 years old male from Dharan, Sunsari residing in Hamro Ghar Rehabilitation centre, Thimi, Bhaktapur) was pessimistic towards his study. He says: "If I had studied, it would have been better for me. Now if any one relatives or family circle comes to talk with me, then the first question they asked me is about my level of study, in which level I am studying. I have not completed my schooling and my friends are in university."

When people talk about education Prakash feels odd. Sometimes he thinks he should study but again he says if he studies again, he may repeat the same behavior. He further more says,

"I did many mistakes in my schooling too. Teacher use to say this and that and I don't like to work in direction. Now, here in rehabilitation centre I have to also follow the direction but now I am slowly habituated to be in discipline or direction. When I go back to school again if any one tries to move me or tries to control me in direction, there may be and because of my attitude, I can go back to injecting drugs."

From the narrative inquiry of my participant, I made meaning was that strict rules in school make students to do anti social activity which may further provides an environment for the use and abuse of drugs. Dhital, Subedi, Gurung and Hamal (2001) also state that anti social activity like use and abuse of drugs are the result of frustration, anger and corporal punishment to children.

Prakash was pessimistic towards his education. $\mathrm{He}$ says now he will not go to school but now he is thinking of doing some job or taking some VET courses. He likes to work as a technician. It will be good for his family too and he will be away from drugs.

Bhuvan (pseudo name, 19 years old male from Bhaktapur residing in Hamro Ghar Rehabilitation centre, Thimi, Bhaktapur) thinks education is an important think and he was getting good education but he ignored it. He says:

"At first I was good in my studies but when I got involved in drugs than I didn't care it. When I started taking drug, how much I read but I didn't remember it."

He opined education is important and added: In my case now it's too late. Now if I got an opportunity than also I won't study. When I was in suffering period, I learnt motorbike repairing and also A/C maintenance but both where incomplete. I like to pass SLC but don't like to go school for studies. Honestly I don't want to study.

Listening to the Bhuvan interview I made meaning was that injecting drug users have no will to study and if they study then there is less possibility of completion for their study. Their body is totally dependent on drugs and by their inner feelings they don't like to study. Shrestha (2012) also states that drug dependency and school dropout makes drug users low self esteem towards their education and finally they quit their education and choose their drug life. 


\section{Findings and Discussion}

Regarding my research question i.e. how do injecting drug users perceive their vocational education and training? It was found that my participant's perception towards VET was mixed. Some of them had a negative perception, while some of them had positive perception. But the common understanding was that every one of my participants knows that VET is an important aspect of their life. My participants did not have any intention of continuing their further education but were willing to do VET. Upon some digging, it became evident that the participants who had a sound schooling or education or learning experience before involving in use and abuse of drugs shared positive perception towards their VET. On the other hand, the participants who did not have sound educational history did not shared positive perception. They spent their time hanging around with their peers.

Conclusively, for my study question, I understand that my participants had understood the importance of VET for their future but where not willing to continue. My participants considered getting a job in order to fulfill their immediate needs without getting their further education, but has the desire to do VET courses. My participants had strong belief that they were not capable to study academic courses due to their habits of use and abuse of injecting drugs.

Injecting drug users knows the importance of VET in their life but the use and abuse of drugs made their study unmanageable and incomplete. Singh and Rajpoot (2012) also state that due to drug use and abuse it makes an individual, family and educational life unmanageable.

Injecting drug users feel guilty about their study not only of their peer who have done well on their study but also their junior brothers and sisters who have done good progress in their study. Niraula, Singh, Nagesh and Shyangwa (2006) also states that one of the role of rehabilitation centers were to provide enabling environment where drug users could think and realize their past and go forwards for their new life.

Use and abuse of drugs not only make individual negative feeling towards peers, family and society but also in education also. Use and abuse of drug make loss on their education and also lacks from different opportunities. Madhav and Yadhav (2012) also state that the use and abuse of drugs leads towards physiological and psychological dependency towards drugs which creates regular threat to their family and worsen their family life with an unexplained reason. If an individual is in drug use and abuse and getting that individual to marriage does not let him/her to quit the use and abuse of drug.

Injecting drug users perceive no will to study, and if they again start their study then there is less possibility of completion for their study. So, rehabilitation centre should play a vital role for vocational rehabilitation. Their body is totally dependent on drugs and by their inner feelings, they do not like to study.

Injecting drug users are the reflection of parents, family, peer and ultimately the society. A good nurturing home and society will produce socially accepted children. After scrutinizing the lived experiences and perceptions of all of the participants, it was revealed that the main problems that led to them being injecting drug users were companion pressure, poor surroundings, curiosity and lack of education with respect to harm of use and abuse of drugs. From my participants interview it can be seen that a child learns morals and ethics from home, school, surrounding and society. This is where he/she is supposed to be nurtured and prepared for a better future. However, home, school, and society are also places where child can learn different anti social activity and delinquency including injecting drugs.

It confirms with Bandura's social learning theory that claim that injecting drug users learned via observation, imitation and modeling (Bandura, 1969). 
Similarly, a sound educational background is also a major part of the interface because it directly impacts the social construct and life. Also, social construct and education go hand in hand because in my understanding, education plays a vital role to improve social construct and the other way around is also true. None of my participants belonged to an educated home and my participants are also not willing to carry out their further study. This reflects the interface between education and social construct and its impact on my participant life. Most of my participants' life experience before coming to the rehabilitation centre was full of drug dependence and enjoyment on drugs. The Injecting drug users came from homes with broken family, or absence of one or both parents, bad peer/social influence. The social construct directly influenced their lives (Singh \& Rajpoot, 2012). Also, attachment, commitment, involvement, and belief between my participants and the various facets of social construct were relatively weak. This led them to commit anti-social acts including intake of more injecting drugs and it severely impacted their own lives too (West, 2005). So, VET course and vocational rehabilitation is essential for specially needs like injecting drugs users.

\section{Conclusion}

Finally, this research brings to the fore that every one of my participants has common understanding that VET is an important aspect in their life but my participants are pessimistic towards their study but on the other hand they were optimistic towards VET. Those who were good students and had affirmative impression towards school before involving in injecting drug users understood the importance of VET after joining rehabilitation centre had positive perception in relation to VET. They valued VET and VET course is highly important for their social and financial rehabilitation. They thought earning money is much more important than getting education and the level of education they had acquired will be enough to manage their life. For the financial upgrading, VET is one of most important aspects which not only help to upgrade their economic status but also for social integration in their own society.

\section{Competing interests}

The author declares that there is no competing interest. Ethical consideration and consent to participants Before the data collection, an oral ethical clearance was taken from the drug rehabilitation centers. An oral informed consent was taken from the individuals with substance use disorder. They were also informed about the purpose of the study, their voluntariness in participation and no any foreseeable risk and harm in the study.

\section{References}

Aryal, S. P. (2010). Survey on hard drug users in Nepal: A practice for policy analysis and advocacy. Consultative meeting December 13 14, 2010: Bangkok. Retrieved from http://www. unescap.org/stat/meet/HLCM/Nepal-1.pdf

Atkinson, P. \& Hammersley, M. (2007).Ethnography: Principles in practice (3rd ed.). New York: Routledge.

Bandura, A. (1969). Social learning theory. New York: General learning press. R e t r i e v e d from http://www.jku.at/org/content /e54521/e54528/e54529/e178059/Bandura_ SocialLearningTheory_ger.pdf

Brewer, J. D. (2005). Ethnography. London: Open University Press.

Dhital, R., Subedi, G., Gurung, Y. \& Hamal, P. (2001). Alcohol and drug use in Nepal with reference to children. Kathmandu: Child workers in Nepal concerned centre.

Fetterman, D. M. (2010). Ethnography: Step-by-step (3rd ed.). New York: Sage

Goode, E. (2011). The sociology of drug use. New York: Sage. Retrieved fromhttp://www.sag epub.com/oswmedia3e/study/chapters/ handbooks /handbook6.2.pdf

Madhav, B. K. \& Yadhav, B. N. (2012). Drug abuse: 
A medicolegal aspect. Journal of Drug Delivery and Therapeutics, 2(6), 86-89. Retrieved from http://jddtonline.info/index.php/jddt/article/ viewFile/313/197

National centre for STD and AIDS prevention. (2006). National data HIV/AIDS. Kathmandu: Author.

Niraula, S. R., Chhetry, D. B., Singh, G.K., Nagesh, S. \& Shyangwa, P.M. (2006). Role of rehabilitation centers in reducing drug abuse problem in a town of eastern Nepal. Kathmandu University Medical Journal, 4(4), 448-454. Retrieved from http://www.kumj.com.np/ issue/16/448-454.pdf

Pradhan, S. N., Sharma, S. C., Shrestha, M. R. \& Shrestha, S. (2012). A study of depression among patient of substance use disorder. Journal of Kathmandu Medical College, 1(2). Retrieved from http://www.jkmc.com.np/ issue/2/96-99.pdf

Richard, T. (2011). Vocational training for needy ones. New York: Modern Publishers.

Sharma, B. (2007). Drug problem, treatment and rehabilitation in Nepal. The Nepalese Journal for Drug Control, 1(1) 27-28.

Shangwa, P. M., Joshi, D \& Lal, R. (2007). Alcohol and other substance use/abuse among junior doctors and medical students in a teaching institute. Journal of Nepal Medical Association, 46(167), 126-129. Retrieved from http://www .jnma.com.np /files/pdf/vol/46/no/3/issue/ 167/year/2007/month/jul-sep/original_article/ 126-129.pdf

Shrestha, N. (2012). Drug injecting practice among adolescence in pokhara sub metropolitan city, Nepal. Journal of Allied Health Science, 2(1). Retrieved from http://pu.edu.np/university/wp content/uploads/2013/03/JHAS-2012-Vol-2 2.pdf
Sinha, A. (2009). Service delivery approach for post rehabilitation care of drug users. Kathmandu: Save the Children.

Singh, N. P. \& Rajpoot, S. (2012). Drug abuse among rural youth: A study in Agra. Golden Research Thought,1(9), 1-4. Retrieved from http://aygrt.isrj.net/UploadedData/1038.pdf

Smith, J. (2014). Vocational education and training. New York: Sage.

United nation office of drug control. (2011). Profile, drug use pattern, risk behavior and selected bio makers of women drug users from seven sites in Kathmandu. Kathmandu: Author. Retrieved from http://www.unodc.org/ documents/ ........._drug_users_from_seven_ sites_in_Nepal.pdf

West, R. (2005). Theory of addiction. Oxford: Blackwell publishing. Retrieved from http://66.199.228.237/boundary/addiction/ Theoryofaddictionfirsthalf.pdf 